\title{
The improvement in aerobic capacity, disease activity, and function in patients with rheumatoid arthritis following cardiac rehabilitation program: A single-center, controlled study
}

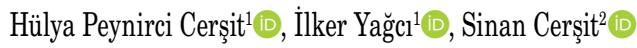 \\ ${ }^{1}$ Department of Physical Medicine and Rehabilitation, Marmara University School of Medicine, Istanbul, Turkey \\ ${ }^{2}$ Department of Cardiology, Istanbul Kartal Koşuyolu Yüksek Ihtisas Training and Research Hospital, Istanbul, Turkey
}

Received: June 20, 2018 Accepted: December 15, 2018 Published online: April 26, 2019

\begin{abstract}
Objectives: This study aims to evaluate the effect of cardiac rehabilitation (CR) on disease activity, functional status, fitness, and modified cardiovascular disease (CVD) risk factors in patients with rheumatoid arthritis (RA) with a moderate disease activity.

Patients and methods: This single-center, controlled study included a total of 60 female RA patients (mean age 57.5 years; range, 50 to 64 years) with moderate disease activity according to the Disease Activity Score-28 (DAS28) between January 2014 and June 2015. The patients were divided into two equal groups as those receiving CR program $(\mathrm{n}=30)$ and those receiving home exercise program (HEP; $n=30$ ). The patients were evaluated at baseline, at Weeks 10 and 24 using exercise tolerance test (i.e., The Metabolic Equivalent of Task [MET] and maximal oxygen uptake [ $\left.\left.\mathrm{VO}_{2} \max \right]\right)$, Six-Minute Walk Test (6MWT), DAS28, Health Assessment Questionnaire (HAQ), modified Systematic Coronary Risk Evaluation (mSCORE), Short Form Health Survey-36 (SF-36), and Beck Depression Inventory (BDI).

Results: There was a significant improvement in the $\mathrm{VO}_{2} \max (\mathrm{p}<0.001), \mathrm{MET}(\mathrm{p}<0.001)$, DAS28 $(\mathrm{p}<0.001), \mathrm{HAQ}(\mathrm{p}<0.001), \mathrm{BDI}(\mathrm{p}=0.005)$, SF-36 physical function $(\mathrm{p}=0.039)$, pain $(\mathrm{p}<0.001)$ and vitality subscale scores $(\mathrm{p}=0.008)$, and $6 \mathrm{MWT}(\mathrm{p}<0.001)$, after the initial and repetitive exercise programs in the CR group compared to the HEP group. At the end of Week 24, full compliance with HEP was higher in the patients with CR group, compared to the HEP group $(\mathrm{p}<0.001)$. There was no significant effect of supervised exercise program on the mSCORE, although systolic blood pressure $(\mathrm{p}=0.033)$ and resting heart rate $(\mathrm{p}=0.049)$ were significantly improved in the CR group versus HEP group. Conclusion: Based on our study results, supervised exercise program cannot reduce CVD risk as assessed by the mSCORE, although it improves physical fitness, disease activity, and functional outcomes which may reduce traditional CVD risk factors in patients with RA.
\end{abstract}

Keywords: Cardiac rehabilitation, cardiovascular risk, home exercise, rheumatoid arthritis.

Rheumatoid arthritis (RA) is a chronic inflammatory disease characterized by symmetric peripheral synovial joint involvement. It can also cause systemic involvement via tissue and organ damage ${ }^{[1]}$ Extra-articular involvement may be seen in about $40 \%$ of patients. ${ }^{[2]}$ Extra-articular involvement is related to increased morbidity and early mortality. ${ }^{[2]}$ Cardiovascular (CV) involvement is the most common cause of death in RA. In the literature, CVD risk has been shown to increase by $50 \%$ in RA patients, compared to general population. ${ }^{[3]}$
Rheumatoid arthritis and CVD share similar inflammatory mechanisms. ${ }^{[4]}$ Longer disease duration, higher disease activity, and elevated acute phase reactants are associated with the development of atherosclerosis. ${ }^{[5]}$ In addition to an increased atherosclerosis risk, a higher level of physical inactivity is common in patients with RA, compared to general population. Physical inactivity has been also shown to be associated with decreased life expectancy ${ }^{[6]}$ It is also thought to be an independent risk factor for heart disease such as diabetes mellitus (DM) or hypertension (HT). ${ }^{[7]}$

Corresponding author: Hülya Peynirci Cerşit, MD. Marmara Üniversitesi Pendik Eğitim ve Araştırma Hastanesi, Fiziksel Tip ve Rehabilitasyon Anabilim Dalı, 34899 Pendik, İstanbul, Türkiye. e-mail: hulyapeynirci@gmail.com 
Recent guidelines recommend evaluating and treating the CVD risk in patients with RA. The European League Against Rheumatism (EULAR) suggests using modified Systematic Coronary Risk Evaluation (mSCORE) risk assessment profile for calculation and management of CVD risk in RA patients. ${ }^{[8]}$ Controlling inflammation and disease activity are the most important factors for risk reduction. Furthermore, assessment of general CVD risk factors such as hyperlipidemia (HL), obesity, and smoking is also suggested. ${ }^{[8]}$

Cardiac rehabilitation (CR) is usually described as medically supervised program which helps to improve the health and well-being of individuals with heart diseases. ${ }^{[9]}$ The cornerstone activity of CR programs is regular and well-planned exercises. These programs include exercise training, education on heart-healthy living, and counseling to reduce stress, and help return to an active life. Cardiorespiratory aerobic exercises improve some of the most important RA patient outcomes including function, quality of life, compliance, and pain. Moreover, it appears that aerobic exercise decreases radiological damage and pain and adverse events, indicating that exercises were safe in stable RA. ${ }^{[9]}$ However, there is limited information about the cardiac risk management in patients with RA. Previous studies about exercises in RA have mostly focused on the functional status rather than the cardiac risk management. These studies have emphasized that exercise may improve the Disease Activity Score of 28 joints (DAS28) and Health Assessment Questionnaire (HAQ) scores which are the indicators of disease activity and functional status. ${ }^{[9,10]}$

In the present study, we aimed to compare the effect of CR program and home exercise program (HEP) on disease activity, functional status, fitness parameters, and CVD risk factors in patients with established RA with a moderate disease activity.

\section{PATIENTS AND METHODS}

This cross-sectional, observational study, single-center, controlled study included a total of 60 female RA patients (mean age 57.5 years; range, 50 to 64 years) who met the American College of Rheumatology (ACR)/EULAR 2010 classification criteria $^{[8]}$ with moderate disease activity according to the DAS28 between January 2014 and June 2015. Inclusion criteria were as follows: female sex, age between 45 to 75 years; having a DAS28 score of 3.2 to 5.1. Patients who had a DAS28 score of $<3.2$ or $>5.1$, contraindication for exercise stress test, coronary artery disease, congestive heart failure, peripheral artery disease, or neurological disease which could hinder the use of cycle ergometer or walking, and those with lower extremity deformity, and low mental status were excluded from the study.

Initially, 66 patients who were volunteer to participate in the study were numerated. The patients were randomly divided into two groups as CR and HEP by a web-based shareware. There were 36 patients in CR group and 33 patients in HEP group. Six patients in the CR group and three patients in the HEP were excluded from the study due to incompliance with the hospital-based exercises or irregular follow-ups. Finally, the study was completed with 30 patients in each group. The patients with RA were managed by followed-up under tight control in a single rheumatology center and all treatment decisions were made based on the target-to-treat strategy during exercise program. A written informed consent was obtained from each patient. The study protocol was approved by the Marmara University, Faculty of Medicine, Medical Ethics Committee (ID: 09.2013.0412). The study was conducted in accordance with the principles of the Declaration of Helsinki.

Demographic data and disease activity were assessed by the first clinician using a standardized form. Age, height, weight, body mass index (BMI), anti-citrullinated protein antibodies (ACPA), rheumatoid factor (RF), lipid profiles, erythrocyte sedimentation rate (ESR), C-reactive protein (CRP) values, left ventricular ejection fraction (LVEF), occupation, prevalence of HT, DM, HL, chronic kidney disease (CKD), thyroid disorders, respiratory system diseases, smoking, RA duration, medical drug regimens, and presence of extra-articular involvement were recorded. The Short Form Health Survey-36 (SF-36), DAS28, HAQ, and Beck Depression Inventory (BDI) forms were filled out by each patient. The DAS28 score and mSCORE risk profile were calculated. All patients were evaluated by a cardiologist experienced with echocardiography and electrocardiography (ECG) to eliminate exercise-dependent risks and referred to the second clinician who performed the exercise testing and Six-Minute Walk Test (6MWT) (Figure 1). All participants in the study underwent a standardized education including CVD risk factors in RA, importance of physical activity, healthy diet, and health consequences of smoking.

\section{Follow-up parameters}

The SF-36 is a generic measure for assessing the quality of life which has eight subscales such as physical functioning, physical role limitations, pain, 


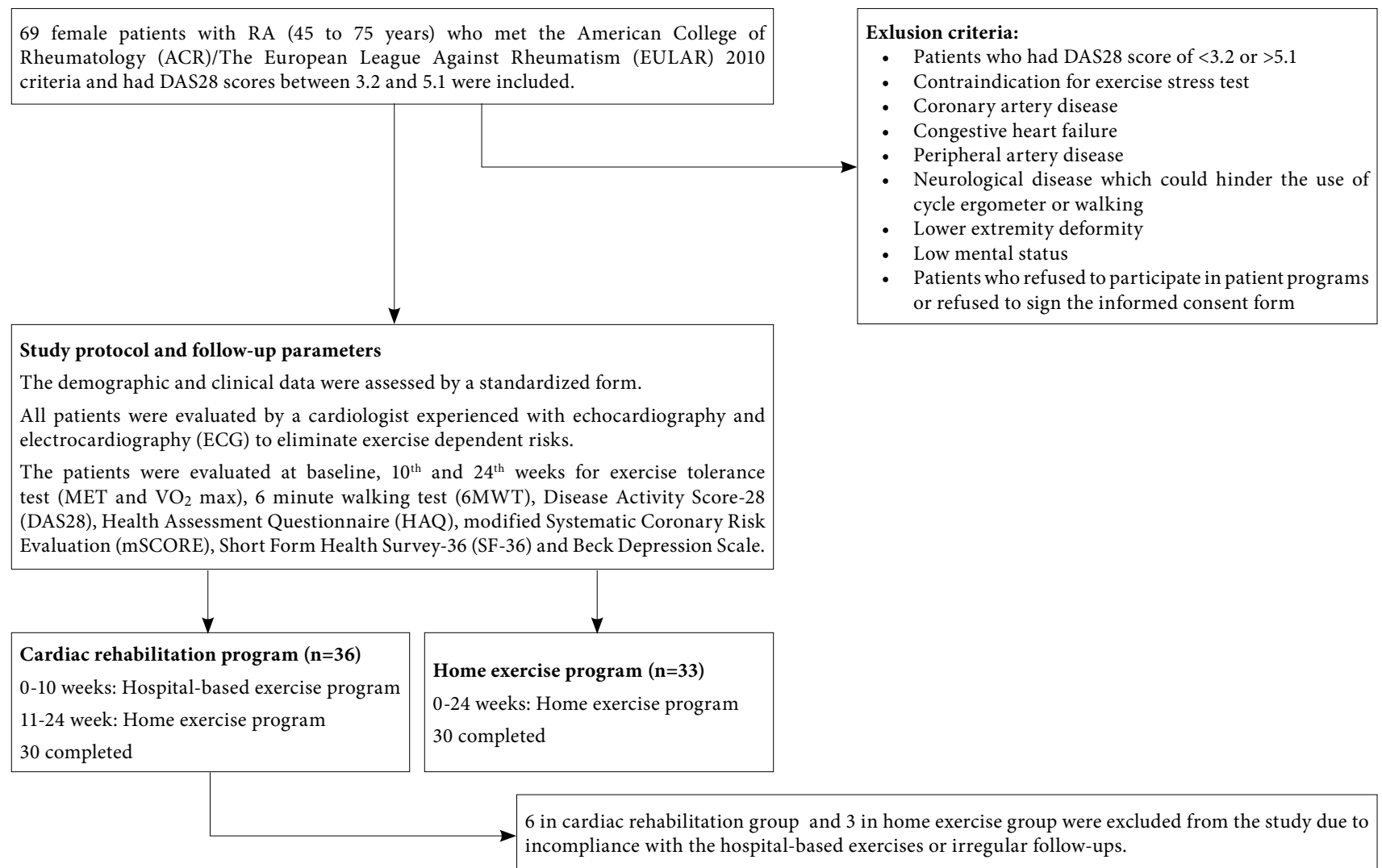

Figure 1. Study flowchart.

general health perceptions, vitality (energy), social function, emotional status, and mental health. The Turkish validity and reliability studies were done by Koçyiğit et al. ${ }^{[1]}$

The HAQ was developed to assess functional disability in patients with RA. In eight subscales constituting of dressing and personal care, stand up, getting out of bed, eating and drinking movements, walking and climbing stairs, washingtoilet, reaching high and low, hand grip and daily activities, it includes questions related to the 20 daily living activities. Total scores between 0-1 indicate mild; $1.1-2$ moderate, and 2.1-3 severe functional loss. ${ }^{[12]}$ Validity and reliability studies in Turkish were conducted by Küçükdeveci et al. ${ }^{[13]}$

The BDI is a scale which consists of 21 questions, where behaviors related with depressive affect are questioned. The validity and reliability studies were carried out by Hisli ${ }^{[14]}$

The 6MWT measures the submaximal exercise capacity indirectly which is commonly used in cardiopulmonary rehabilitation. It is reported to be correlated with aerobic capacity $\left(\mathrm{VO}_{2} \max \right)$.
Before starting the test, patients were seated for $15 \mathrm{~min}$ to rest. Although normal values can be changed due to age, sex, and BMI, values between 400 to 700 meters were accepted as normal range. Absolute contraindications include unstable angina and myocardial infarction within the last one month, while resting blood pressure (BP) over $180 \mathrm{mmHg}$ and resting heart rate (HR) above 120 beats per minute are considered relative contraindications for the test. Minimal significant change for improvement criterion in the $6 \mathrm{MWT}$ was found to be 54 meters according to a previous study. ${ }^{[15]}$

The mSCORE risk assessment profile is based on the EULAR guidelines. ${ }^{[8]}$ Ten-year risk of fatal CVD was calculated using variables such as age, sex, smoking, systolic blood pressure (SBP), and total cholesterol (TC)/high-density lipoprotein (HDL) ratio, according to the SCORE model. Then, a 1.5-multiplication factor was used, when the patient with RA meets two of three criteria which are disease duration of more than 10 years, RF or ACPA positivity, presence of certain extraarticular manifestations. ${ }^{[8]}$

The DAS28 is a measure of disease activity in RA. It considers 28 tender and swollen joint counts, 
general health $(\mathrm{GH}$; patient assessment of disease activity using a $100 \mathrm{~mm}$ visual analog scale [VAS] with $0=$ best, $100=$ worst), plus levels of an acute phase reactant (either ESR $[\mathrm{mm} / \mathrm{h}]$ or CRP $[\mathrm{mg} / \mathrm{L}])$. A DAS28 of higher than 5.1 indicates active disease; less than 3.2 low disease activity; and less than 2.6 remission. ${ }^{[16]}$

The exercise tolerance test was applied in CR unit two days after the first evaluation. Contraindications for exercise test were assessed by a cardiologist. Cycle ergometer (Ergoline Ergoselect 2 model 600 and Opticare software program) was used to assess the exercise capacity. ${ }^{[17]}$ All patients were instructed to wear comfortable clothes, stopped eating/drinking for three hours before their arrival, and did not smoke before the test. Maximum heart rate (MHR) and target heart rate (THR) range were calculated according to age and sex, and Karvonen formula [(MHR- resting HR $) \times \%$ intensity + resting HR], respectively. ${ }^{[18]}$ During the test, the patient started cycling with 30 watts pedal load and 15 watts increment was applied every two min with a constant pedaling speed of 55 to 65 per min. If THR was reached or the patient wanted to stop due to fatigue, the test was stopped. Reached maximum pedal load in watts, maximal oxygen consumption in min per $\mathrm{kg}$ or the metabolic equivalent of task (MET) $(\mathrm{mL} / \mathrm{kg} / \mathrm{min})$ and maximal energy consumption $(\mathrm{kcal} / \mathrm{min})$ were recorded. The data were used to develop individualized rehabilitation program of patients in CR group and also used as a follow-up criterion of fitness parameters for both groups.

Rehabilitation approach in the CR group: Initially the ratio of maximum load to patient body weight (watt $/ \mathrm{kg}$ ) was calculated. The ratio was used as an indicator of physical fitness. The values lower than $1.4 \mathrm{watt} / \mathrm{kg}$ indicated an untrained person or patients with moderate-to-high risk for cardiac complications during physical stress according to the recommendations of the American Heart Association. ${ }^{[19]}$ If the ratio was lower than 1 watt $/ \mathrm{kg}$, the patients started the program with low-intensity intermittent training for providing the compliance of the patient with the program. When the ratio was $\geq 1$, exercise program was continued with constant HR (endurance training) method. Individual exercise programs were revised weekly by assessments including the Borg scale, MHR at maximal load, ECG, and $\mathrm{BP}$ monitorization during the exercises.

Each training session included reduced load warming and cooling periods for five $\mathrm{min}$ in the beginning and the end. In the intermittent training program, the patients performed one-min low intensity and maximum load consecutively for 20 min under supervision of the second clinician. Using the constant HR method, the maximal load at THR was recorded with the exercise testing. In the program, the patients exercised without exceeding THR. The THR was kept in constant with changing the load automatically by cycle ergometer.

Each exercise session was ended with stretching and strengthening exercises. Biceps, triceps, deltoid, quadriceps, hamstrings, abductor muscle groups were trained in the muscle strengthening program. Strengthening exercises were planned with calculation of one repetition maximum (RM) method. The maximum load which can be hold by three different large muscle groups of lower and upper extremities was determined. Each muscle was strengthened with $3 \times 10$ repetitive isotonic contractions with up to $75 \%$ resistance of one RM.

Hospital-based exercise program was performed three days per week between Weeks 1 and 10. After Week 10, HEP was performed in the patients and they were assessed at Week 24. During the HEP, the patients were called weekly via telephone by the second clinician to increase compliance with the exercise program. At Week 24, the patients were questioned with a simple questionnaire about their compliance to HEP. The patients who did not perform the aerobic exercise program were accepted as incompliant patients.

HEP group: According to the exercise capacity, the patients were recommended to perform a HEP. The program included 20 to 45 min brisk walking for three times a week and proceeding with stretching and strengthening exercises of lower and upper extremity muscles. The training program was planned for each patient individually by the second clinician. The patients were called weekly via telephone and were encouraged to comply with the HEP. The patients were evaluated at Weeks 10 and 24. Their compliance with HEP was also questioned at Week 24.

\section{Statistical analysis}

Statistical analysis was performed using the IBM SPSS for Windows version 19.0 software (IBM Corp., Armonk, NY, USA) and R free software v.3.5.1 with nparLD package (Institute for Statistics and Mathematics, Vienna, Austria). Power analysis was performed before the study. Based on a previous study, the effect size was $17 \%$ for $\mathrm{VO}_{2}$ max parameter. ${ }^{[20]}$ Minimum 11 subjects in each group would be necessary to detect significant difference at an alpha level of 
$5 \%(=0.05)$ with an $80 \%$ probability $(=0.2)$. Normal distribution of data was analyzed using the KolmogorovSmirnov test. Descriptive statistics were expressed in mean \pm standard deviation (SD) or number and frequency. Categorical values were analyzed using the chi-square test. Repeated measures analysis of variance (ANOVA) and Brunner-Langer test (non-parametric repeated measures ANOVA) and analysis of covariance (ANCOVA) with one between-subjects factor (group: CR vs. HEP) and one within-subjects factor (time: baseline vs. Week 10 vs. Week 24) were used to investigate the changes in disease activity, functional status, fitness, and CVD risk factors between the groups at the three different time points. The Tukey honestly significant difference (HSD) method was used to detect where the differences in the evaluation points occurred (baseline vs. Week 10 vs. Week 24). A $p$ value of $<0.05$ was considered statistically significant with $95 \%$ confidence interval (CI).

\section{RESULTS}

The comparison of baseline characteristics between the groups is shown in Table 1. Age, height, weight, body mass index, ACPA and RF levels, LVEF, occupation, prevalence of HT, DM, HL, CKD, thyroid disorders, respiratory system diseases, smoking status, RA duration, medical drug regimens and presence of extra-articular involvement were similar between the groups.

Fitness parameters: While the CR and HEP groups had similar MET values at baseline, MET values of $C R$ group at Weeks 10 and 24 were significantly higher than HEP group $(\mathrm{p}<0.001)$. A statistically significant difference was also detected between the values of baseline and Week 10 and between baseline and Week 24 in favor of the CR group according to the Tukey HSD method (F Week 10 and baseline: $\mathrm{p}<0.001$; Week 24 and baseline: $\mathrm{p}=0.001$ ) (Figure 2). Statistical analysis of the $\mathrm{VO}_{2}$ $\max (\mathrm{p}<0.001)$, maximum energy consumption $(\mathrm{p}=0.001)$, maximum load $(\mathrm{p}<0.001)$, and $6 \mathrm{MWT}$ $(\mathrm{p}<0.001)$ parameters had a significantly similar pattern of results with MET. Although two groups had similar values at baseline, values of CR group at Weeks 10 and 24 were significantly better than HEP group (Table 2). In ANCOVA test, all fitness parameters had significant differences between two groups at different time points (baseline vs. Weeks 10 and 24) (for all p<0.05) (Table 5).

Functional measurements: The parameters about the functional scores and DAS28 are demonstrated in Table 3. The SF-36 physical function and pain subscale scores of CR group were significantly higher than HEP group [( $\mathrm{p}=0.039 ; \mathrm{p}<0.001$, respectively $)]$ although no statistically significant difference in the SF-36 physical function subscale was observed between the values of baseline vs. Week 24 in favor of CR group according to the Tukey HSD method. In SF-36 vitality subscale, CR group had lower scores at baseline which increased at Week 10 (Tukey HSD $\mathrm{p}=0.001$ ) in CR group, and reached a similar level for both of the groups at Week 24 (Tukey HSD $\mathrm{p}=0.021$ ) (ANOVA $\mathrm{p}=0.008$ ). The SF-36 general health perception, physical role subscales, social function, emotional status, and mental status subscales were similar between two groups at the three different time points. The HAQ scores of CR group at Weeks 10 (Tukey HSD $\mathrm{p}<0.001$ ) and 24 (Tukey HSD $\mathrm{p}<0.001$ ) were found to be lower than the scores of HEP group (ANOVA $\mathrm{p}<0.001$ ). A significant difference regarding the BDI was observed in CR group. At baseline, both groups had similar scores, although the scores of CR group were found to be statistically lower than HEP group $(\mathrm{p}=0.025)$.

The ANCOVA test revealed that the SF-36 vitality and emotional status subscales and HAQ scores were significantly different between two groups at different time points (baseline vs. Weeks 10 and 24), although the SF-36 physical role, pain, physical function, general health perception and social function subscale and BDI scores were significantly different at only Week 10 (for all $\mathrm{p}<0.05)$ (Table 5).

Disease activity measurements: A statistically significant difference was found between two groups in terms of DAS28 scores $(\mathrm{p}<0.001)$. The baseline scores were similar for both groups; however, DAS28 scores significantly decreased in CR group and were significantly lower than HEP group $(\mathrm{p}<0.001)$. The number of patients who showed significantly $\geq 0.6$ improvement in DAS28 scores was 20/30 (65\%) in CR group and $4 / 30(15 \%)$ in HEP group $(\mathrm{p}=0.04)$. In repeated measurements, global assessment scores of CR group were significantly lower than HEP group $(\mathrm{p}<0.001)$. There were no statistically significant differences in baseline CRP and ESR values between the groups. The number of swollen joints was similar between the groups at different time points, although a significant difference was observed regarding the tender joint count between the groups in repeated measurements $(p<0.001)$. At baseline, scores were similar for both groups, while the tender joint count significantly decreased in CR group after repeated measurements $(\mathrm{p}<0.001)$. 


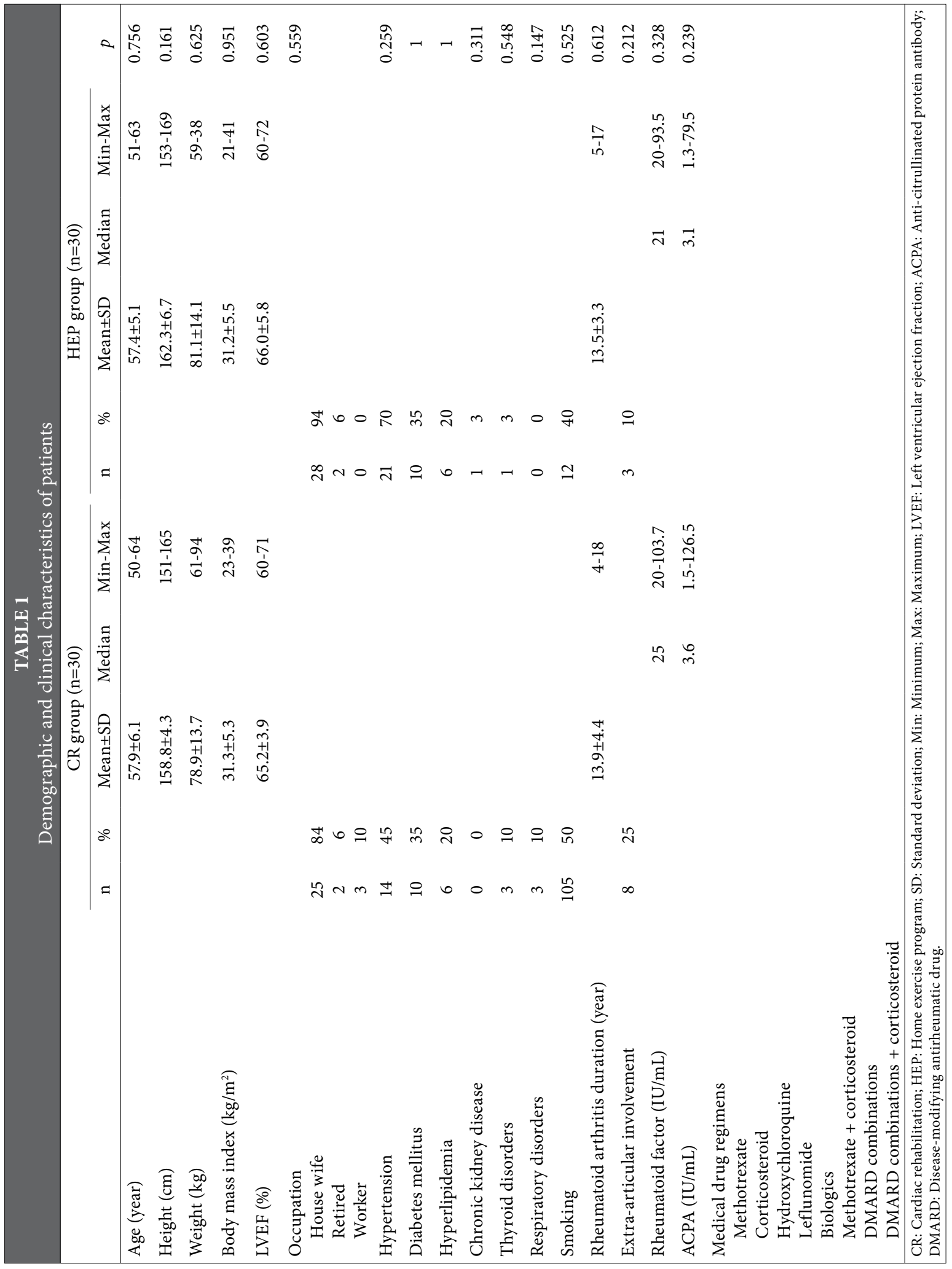




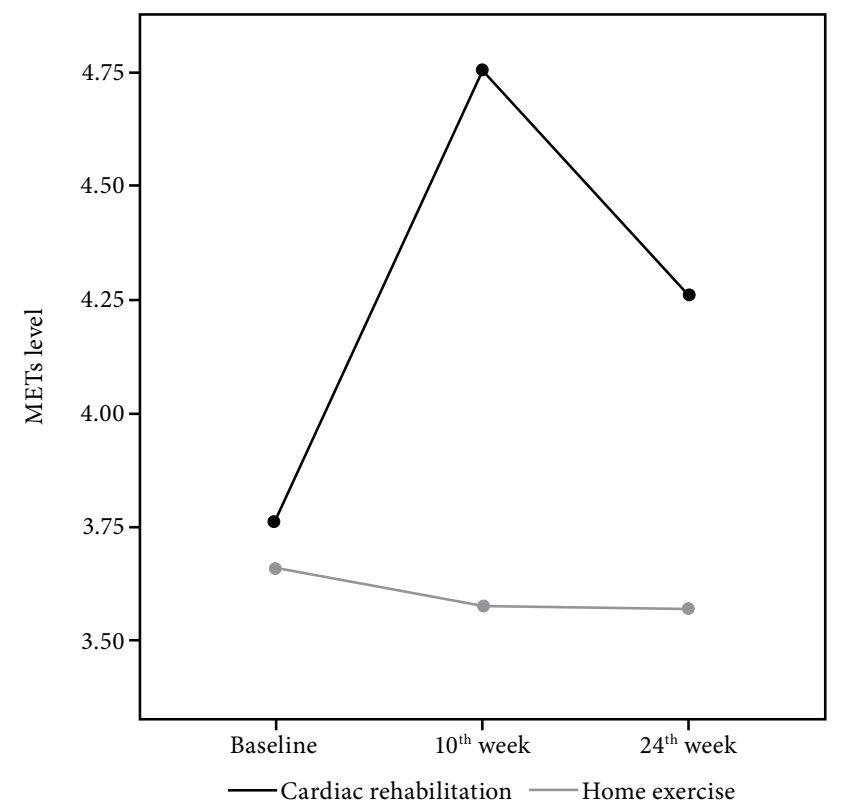

Figure 2. Changes in MET values from baseline to Weeks 10 and 24 for cardiac rehabilitation versus home exercise groups. MET: Metabolic equivalent of task.

According to the ANCOVA test, DAS28 and global assessment scores and tender joint count were significantly different between two groups at different time points (baseline vs. Weeks 10 and 24), although swollen joint count was significantly different at only Week 10 (for all $\mathrm{p}<0.05$ ) (Table 5).

Cardiovascular risk analysis: All patients included in the study had a mSCORE risk profile with a mean value of 3 . The mean values exceeded 3 in 50/60 patients. There was no significant difference regarding the mSCORE risk profile analysis between the groups at different time points. A significant decrease was observed in the SBP in CR group $(\mathrm{p}=0.033)$. However, TC/HDL ratio was similar between groups. The resting HR of both groups were similar before the study, although in CR group, there was a statistically significant decrease during follow-up $(\mathrm{p}=0.049)$ (Table 4).

The ANCOVA test revealed that mSCORE risk profile, SBP, and resting HR were significantly different at only Week 10 between two groups (for all $\mathrm{p}<0.05$ ) (Table 5).

HEP compliance: At the end of Week 24, full compliance with HEP was maintained in 20/30 (65\%) patients in CR group and 9/30 (30\%) patients in HEP group $(\mathrm{p}<0.001)$.

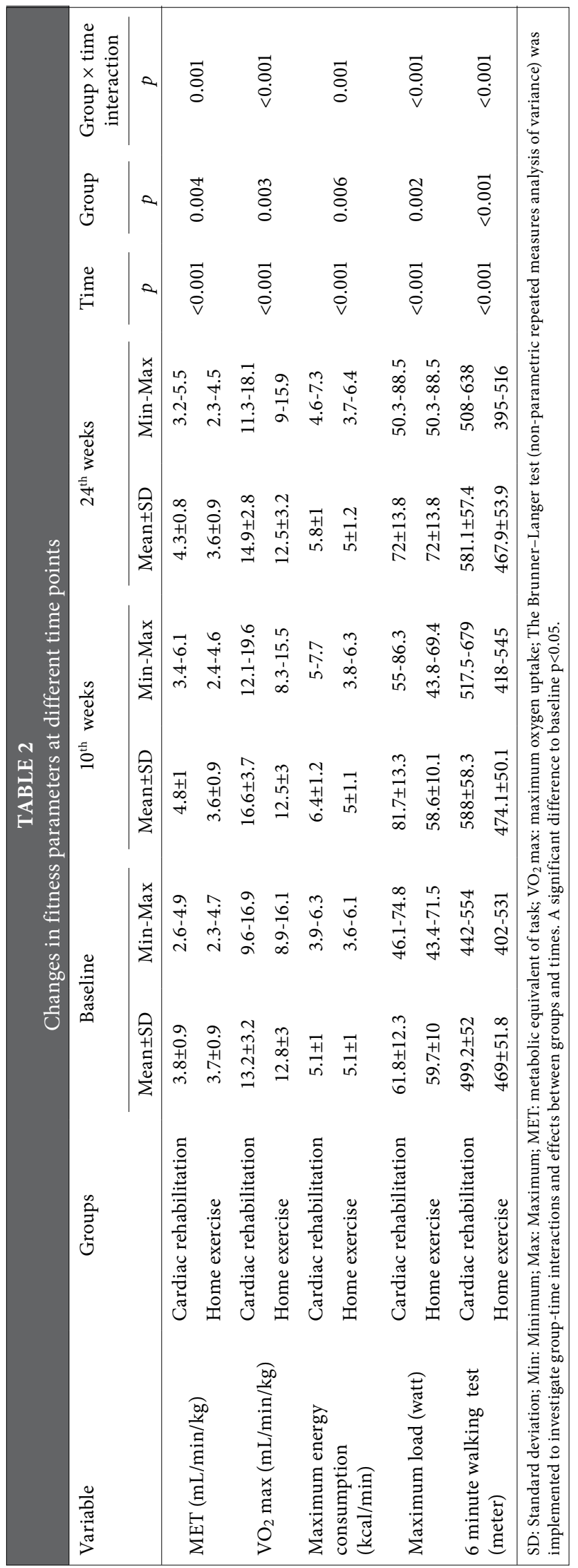




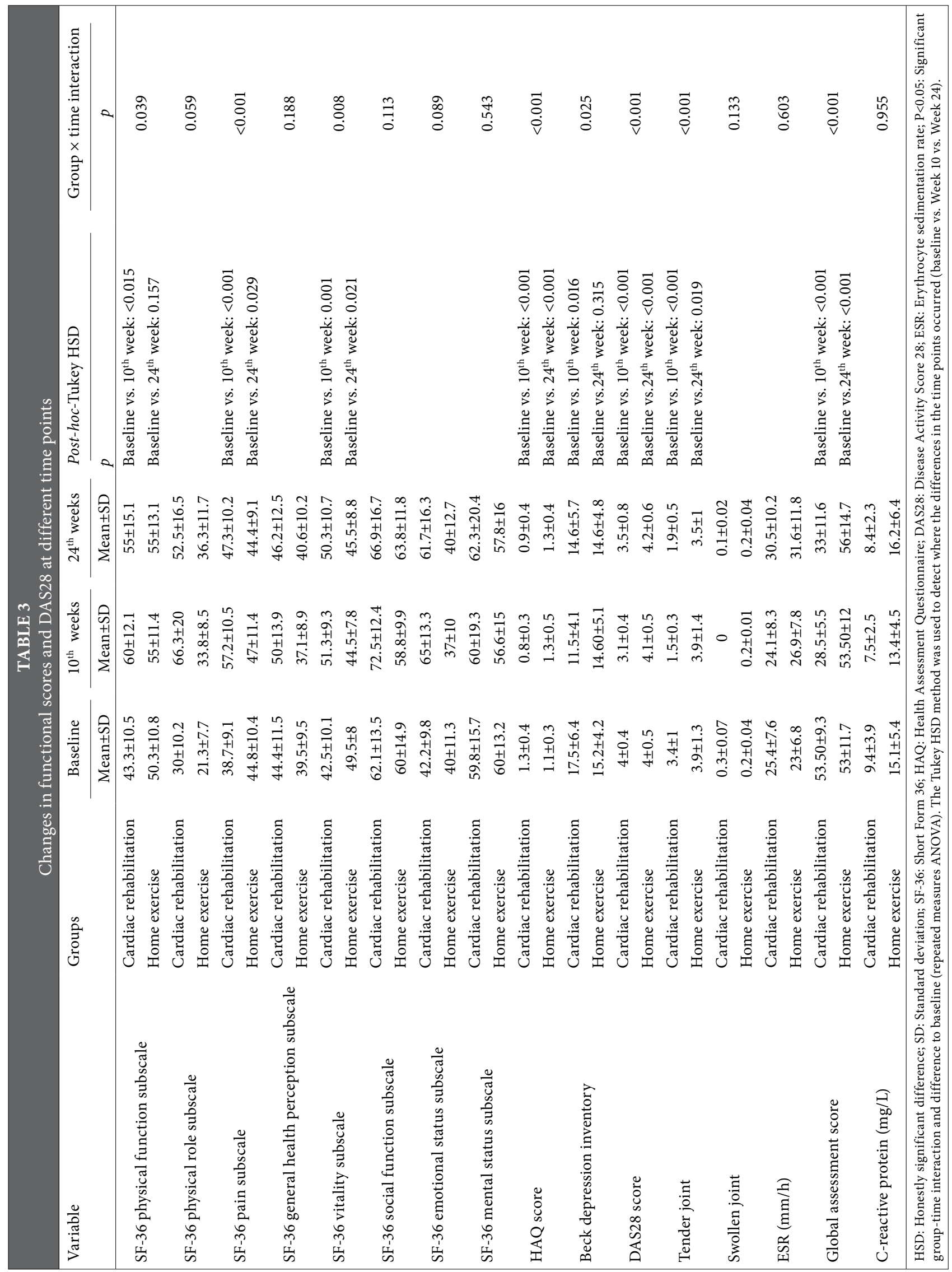




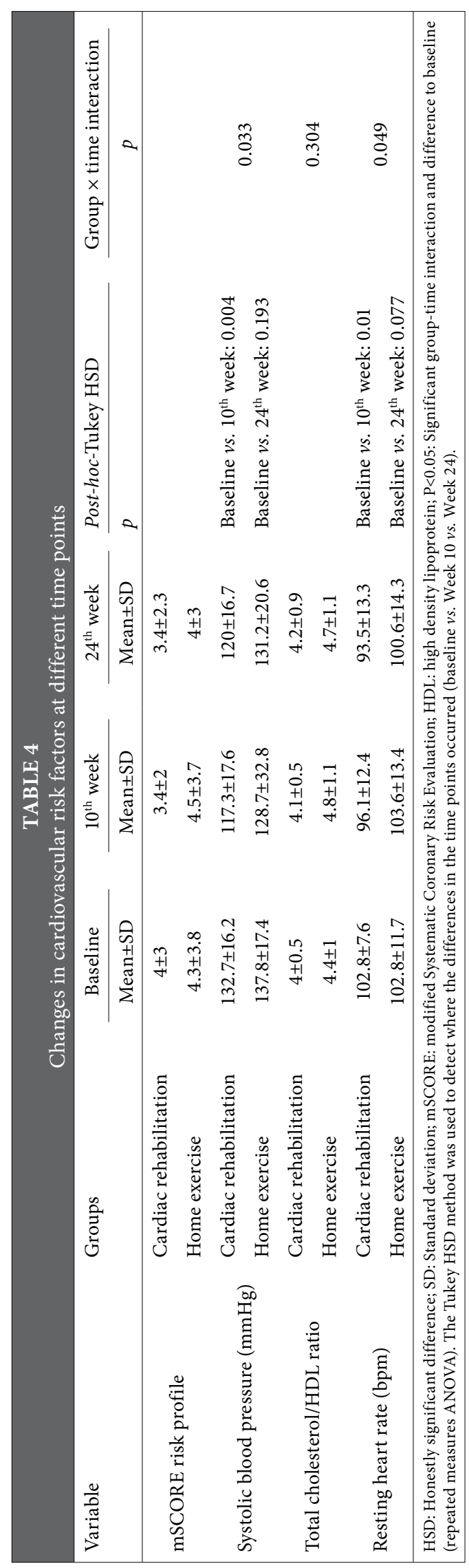

\section{DISCUSSION}

The present study showed that supervised exercise program improved physical fitness, disease activity, functional outcomes, and SBP and resting HR which could reduce the traditional CVD risk factors, although CVD risk reduction could not be demonstrated according to the mSCORE profile in patients with RA.

Cardiovascular disease complications are the leading causes of mortality in RA. ${ }^{[7]}$ Patients with RA have less physical activity and lower aerobic capacity compared to healthy individuals with similar demographic data. ${ }^{[8]}$ In addition, these patients spend more time for low and moderate activities, and physical inactivity is a well-known risk factor for cardiac diseases. ${ }^{[9]}$ In a meta-analysis by Baillet et al., ${ }^{[10]}$ aerobic exercises were found to be safe in RA patients and these exercises were associated with significant improvements in the VAS, quality of life, HAQ, and number of involved joints.

In our study, most of the fitness parameters showed similar changes. At Week 10, the changes of $\mathrm{MET}, \mathrm{VO}_{2}$ max, the maximum energy consumption, maximum load, and 6MWT scores were better in CR group than HEP group. This difference could be associated with the compliance problem in HEP group. The patients in CR group also did HEP during Weeks 10 and 24. The compliance problem in CR group during the HEP period was significantly lower than HEP group.

Previous studies have demonstrated the relationship between increased fitness and reduced CVD risk. Myers et al. ${ }^{[21]}$ reported a $12 \%$ increase in survival with an increase of $3.5 \mathrm{~mL} / \mathrm{kg} / \mathrm{min}$ for $\mathrm{VO}_{2} \max$ in healthy adults. In another study, an increase of $1 \mathrm{~mL} / \mathrm{kg} / \mathrm{min}$ in $\mathrm{VO}_{2}$ max related with a $15 \%$ decrease in CVD mortality risk. ${ }^{[22]}$ It was also shown that fitness of patients with RA was low and these patients had sedentary lifestyle, despite their awareness of the benefits of physical activity. In these patients, supervised exercise programs seemed to have positive effects on fitness, BP, lipid profile, and inflammation. ${ }^{[23]}$ In our study, an increase of $3.5 \mathrm{~mL} / \mathrm{kg} / \mathrm{min}$ in $\mathrm{VO}_{2} \max$ at Week 10 was detected in all patients in CR group. This amount of improvement was equivalent to $20 \%$ improvement in $\mathrm{VO}_{2}$ max. Our findings, therefore, suggest that these patients would have less CVD mortality, if they continue to exercise regularly.

Furthermore, the functional activity levels are decreased in patients with high disease activity 


\begin{tabular}{|c|c|c|c|}
\hline \multicolumn{4}{|c|}{$\begin{array}{l}\text { TABLE } 5 \\
\text { Changes in the assessment points (baseline vs. } 10^{\text {th }} \text { and } 24^{\text {th }} \text { weeks between two groups }\end{array}$} \\
\hline & Cardiac rehabilitation group & Home exercise group & \\
\hline & Mean \pm SD & Mean \pm SD & $p$ \\
\hline Metabolic equivalent of task- $10^{\text {th }}$ week $(\mathrm{mL} / \mathrm{min} / \mathrm{kg})$ & $4.7 \pm 0.1$ & $3.6 \pm 0.1$ & $<0.001$ \\
\hline Metabolic equivalent of task- $24^{\text {th }}$ week $(\mathrm{mL} / \mathrm{min} / \mathrm{kg})$ & $4.2 \pm 0.1$ & $3.6 \pm 0.1$ & $<0.001$ \\
\hline $\mathrm{VO}_{2} \max -10^{\text {th }}$ week $(\mathrm{mL} / \mathrm{min} / \mathrm{kg})$ & $16.4 \pm 0.5$ & $12.7 \pm 0.5$ & $<0.001$ \\
\hline $\mathrm{VO}_{2} \max -24^{\text {th }}$ week $(\mathrm{mL} / \mathrm{min} / \mathrm{kg})$ & $14.7 \pm 0.4$ & $12.7 \pm 0.4$ & $<0.001$ \\
\hline Maximum energy consumption- $10^{\text {th }}$ week ( $\left.\mathrm{kcal} / \mathrm{min}\right)$ & $6.4 \pm 0.2$ & $5 \pm 0.2$ & $<0.001$ \\
\hline Maximum energy consumption- $24^{\text {th }}$ week $(\mathrm{kcal} / \mathrm{min})$ & $5.8 \pm 0.2$ & $5 \pm 0.2$ & $<0.001$ \\
\hline Maximum load-10 ${ }^{\text {th }}$ week (watt) & $80.8 \pm 2.7$ & $59.5 \pm 2.7$ & $<0.001$ \\
\hline Maximum load $-24^{\text {th }}$ week (watt) & $71.1 \pm 2.3$ & $58.8 \pm 2.3$ & 0.001 \\
\hline Six minute walking test- $10^{\text {th }}$ week (meter) & $574.3 \pm 8.3$ & $487.8 \pm 8.3$ & $<0.001$ \\
\hline Six minute walking test $-24^{\text {th }}$ week (meter) & $567.5 \pm 8.6$ & $481.4 \pm 8.6$ & $<0.001$ \\
\hline Short Form 36 physical function subscale- $10^{\text {th }}$ week & $62.8 \pm 4.7$ & $52.2 \pm 4.7$ & 0.029 \\
\hline Short Form 36 physical function subscale- $24^{\text {th }}$ week & $58.4 \pm 3.2$ & $51.6 \pm 3.2$ & 0.057 \\
\hline Short Form 36 physical role subscale- $10^{\text {th }}$ week & $63.4 \pm 6.9$ & $36.6 \pm 6.9$ & 0.009 \\
\hline Short Form 36 physical role subscale- $24^{\text {th }}$ week & $48.9 \pm 7.3$ & $39.9 \pm 7.3$ & 0.391 \\
\hline Short Form 36 pain subscale- $10^{\text {th }}$ week & $59.6 \pm 2.1$ & $44.6 \pm 2.1$ & $<0.001$ \\
\hline Short Form 36 pain subscale- $24^{\text {th }}$ week & $49.7 \pm 2.8$ & $41.9 \pm 2.8$ & 0.056 \\
\hline Short Form 36 general health perception subscale- $10^{\text {th }}$ week & $48.4 \pm 3.4$ & $38.6 \pm 3.4$ & 0.049 \\
\hline Short Form 36 general health perception subscale- $24^{\text {th }}$ week & $44.3 \pm 3.5$ & $42.5 \pm 3.5$ & 0.721 \\
\hline Short Form 36 vitality subscale- $10^{\text {th }}$ week & $53.9 \pm 2.4$ & $41.9 \pm 2.4$ & 0.001 \\
\hline Short Form 36 vitality subscale- $24^{\text {th }}$ week & $52.7 \pm 3.3$ & $43.1 \pm 3.3$ & 0.047 \\
\hline Short Form 36 social function subscale- $10^{\text {th }}$ week & $72 \pm 3.9$ & $59.3 \pm 3.9$ & 0.028 \\
\hline Short Form 36 social function subscale- $24^{\text {th }}$ week & $66.2 \pm 4.3$ & $64.4 \pm 4.3$ & 0.771 \\
\hline Short Form 36 emotional status subscale- $10^{\text {th }}$ week & $64.5 \pm 9.8$ & $37.6 \pm 9.8$ & 0.009 \\
\hline Short Form 36 emotional status subscale- $24^{\text {th }}$ week & $61 \pm 6.9$ & $40.7 \pm 6.9$ & 0.044 \\
\hline Short Form 36 mental status subscale- $10^{\text {th }}$ week & $60 \pm 3.5$ & $56.5 \pm 3.5$ & 0.492 \\
\hline Short Form 36 mental status subscale- $24^{\text {th }}$ week & $62.3 \pm 3$ & $57.7 \pm 3$ & 0.293 \\
\hline Health Assessment Questionnaire score- $10^{\text {th }}$ week & $0.7 \pm 0.1$ & $1.3 \pm 0.1$ & $<0.001$ \\
\hline Health Assessment Questionnaire score- $24^{\text {th }}$ week & $0.8 \pm 0.1$ & $1.4 \pm 0.1$ & $<0.001$ \\
\hline Beck depression inventory- $10^{\text {th }}$ week & $10.9 \pm 1.2$ & $15.3 \pm 1.2$ & 0.017 \\
\hline Beck depression inventory- $24^{\text {th }}$ week & $13.9 \pm 1.2$ & $15.2 \pm 1.2$ & 0.45 \\
\hline DAS28 score- $10^{\text {th }}$ week & $3.2 \pm 0.1$ & $4.1 \pm 0.1$ & $<0.001$ \\
\hline DAS28 score- $24^{\text {th }}$ week & $3.5 \pm 0.1$ & $4.2 \pm 0.1$ & $<0.001$ \\
\hline Tender joint-10 ${ }^{\text {th }}$ week & $1.6 \pm 0.2$ & $3.7 \pm 0.2$ & $<0.001$ \\
\hline Tender joint- $24^{\text {th }}$ week & $2.1 \pm 0.3$ & $3.4 \pm 0.3$ & 0.003 \\
\hline Swollen joint- $10^{\text {th }}$ week & $0 \pm 0.1$ & $0.2 \pm 0.1$ & 0.013 \\
\hline Swollen joint- $24^{\text {th }}$ week & $0.1 \pm 0.1$ & $0.2 \pm 0.1$ & 0.462 \\
\hline Erythrocyte sedimentation rate- $10^{\text {th }}$ week $(\mathrm{mm} / \mathrm{h})$ & $23.8 \pm 2.9$ & $27.2 \pm 2.9$ & 0.395 \\
\hline Global assessment score- $10^{\text {th }}$ week & $28.3 \pm 2.4$ & $53.7 \pm 2.4$ & $<0.001$ \\
\hline Global assessment score- $24^{\text {th }}$ week & $32.8 \pm 3.1$ & $56.2 \pm 3.1$ & $<0.001$ \\
\hline C-reactive protein-10 ${ }^{\text {th }}$ week $(\mathrm{mg} / \mathrm{L})$ & $9.1 \pm 2.2$ & $11.6 \pm 2.2$ & 0.426 \\
\hline C-reactive protein-2 $4^{\text {th }}$ week $(\mathrm{mg} / \mathrm{L})$ & $10 \pm 4.7$ & $14.6 \pm 4.7$ & 0.498 \\
\hline mSCORE risk profile- $10^{\text {th }}$ week & $3.6 \pm 0.3$ & $4.4 \pm 0.3$ & 0.034 \\
\hline mSCORE risk profile- $24^{\text {th }}$ week & $3.5 \pm 0.3$ & $3.9 \pm 0.3$ & 0.396 \\
\hline Systolic blood pressure-10 $10^{\text {th }}$ week $(\mathrm{mmHg})$ & $119 \pm 2.7$ & $133 \pm 2.7$ & 0.001 \\
\hline Systolic blood pressure- $24^{\text {th }}$ week $(\mathrm{mmHg})$ & $121.9 \pm 3.2$ & $129.3 \pm 3.2$ & 0.109 \\
\hline Total cholesterol/HDL ratio-10 $10^{\text {th }}$ week & $4.2 \pm 0.2$ & $4.7 \pm 0.2$ & 0.09 \\
\hline Total cholesterol/HDL ratio- $24^{\text {th }}$ week & $4.4 \pm 0.2$ & $4.5 \pm 0.2$ & 0.587 \\
\hline Resting heart rate- $10^{\text {th }}$ week (bpm) & $96.4 \pm 1.8$ & $103.2 \pm 1.8$ & 0.011 \\
\hline Resting heart rate- $24^{\text {th }}$ week (bpm) & $93.7 \pm 2.5$ & $100.3 \pm .5$ & 0.075 \\
\hline
\end{tabular}


according to previous studies. ${ }^{[24]}$ In our study, HAQ scores were at a level of 1.3 in CR group and in 1.1 HEP group. These scores can be associated with the high ratio of disability of the patients at the beginning of the study. In addition, CR was found to be effective in reducing the levels of disability. At Week 10, the score was 0.78 and at Week 24, the score was redounded to levels of 0.86 . On the other hand, there was a non-significant worsening in HEP group. Our results are consistent with the findings of previous studies. In a study by StavropoulosKalinoglou et al., ${ }^{[20]} \mathrm{VO}_{2}$ max of patients in aerobic exercise program increased by $10 \%$ and $17 \%$ at three and six months, respectively. The HAQ scores also reduced from level of 1.4 to 1.0 value after three months with high-intensity aerobic exercise program. In the control group, worsening HAQ scores were observed, consistent with our findings. In another study with RA patients, van Rensburg et al. ${ }^{[25]}$ found a significant improvement in DAS28 scores, although HAQ scores were similar between the groups. The aforementioned study yielded important results including improvements in subscales of SF-36 such as physical functioning, physical role difficulty and pain in CR group. A decrease in the degree of perceived pain and increase of function in CR group provided improvement in these parameters.

In a meta-analysis by Kelley et al., ${ }^{[26]}$ significant positive effects of exercise on depressive symptoms, anxiety, pain, quality of life, $\mathrm{VO}_{2} \max$, lower extremity muscle strength and balance were demonstrated. In our study, we also had similar results. In the beginning of the study, CR group had moderate depression scores and, at Week 10, they had mild depression scores. The DAS28 scores significantly decreased over time in CR group. An improvement in DAS28 scores of $\geq 0.6$ was detected in $65 \%$ of the patients in CR group and $15 \%$ of the patients in HEP group. This change was related to the decrease in the tender joint count and global disease assessment. Although there was a statistically significant decrease in the ESR values in CR group, there was no difference regarding the CRP values overtime between the groups. Therefore, we could not conclude that the improvement in DAS28 was related with the reduction of inflammation. We believe that there is an effect of exercise on inflammation, although we are unable to demonstrate it using traditional methods. Similarly, according to previous literature, anti-inflammatory effect of exercise was found to be associated with reduction in the visceral fat mass, interleukin (IL)-1 receptor antagonist and increase in IL-10 levels. ${ }^{[27]}$
In the present study, our primary aim was to show the effect of exercise on CVD risk reduction. The Framingham risk score and Heart Score Program were used for the calculation of 10-year fatal CVD risk in patients with RA. ${ }^{[23,28]}$ Recently, the SCORE Risk Index has been recommended by the EULAR guidelines for RA-specific CVD risk calculation. ${ }^{[8]}$ It was modified with multiplier factors. We used the mSCORE method in our study and the median value was $\geq 3$ in 50 of 60 patients. In a study by RosalesAlexander et al., ${ }^{[29]}$ the mean score, which was calculated with mSCORE calculation, was reported to be $3.3 \pm 4$ and the median value was also 3 . It was also reported that $74 \%$ of patients in the Spanish population had a higher value. These results are consistent with our study results. However, we were unable to demonstrate a risk reduction according to mSCORE, although the patients had improvements in fitness, disease activity, and functional outcome parameters.

On the other hand, there are certain controversies regarding the use of SCORE. In a study by Gómez-Vaquero et al., ${ }^{[30]}$ multiplier factors consisting of the ACPA and RF levels, RA duration and extra-articular involvement caused a 1.5 -fold increase in the SCORE, however, it did not yield a statistically significant difference in the CVD risk estimation. In another study, carotid intimamedia thickness and plaque in the carotid artery were not found to be correlated with their SCORE points of the RA patients. ${ }^{[31]}$ In addition, DM, previous heart disease, family history, presence of metabolic syndrome, obesity, and CRP values were not considered multiplying factors. In our study, only two measurements might have influenced the mSCORE calculation: SBP and lipid profile. Although SBP decreased in CR group, TC/HDL ratio remained unchanged, which can be explained with the short duration of follow-up. Altered SBP did not lead to a major change in the calculation of SCORE and, therefore, we were unable to demonstrate a risk reduction in the mSCORE.

This study has certain limitations. The main limitation is the discrepancy of compliance between the groups with an extremely low compliance level in the HEP patients. Second, RA is a multifactorial disease, and that the genetic factors predisposing to inflammation were not investigated in our study. Third, the effect of exercise on inflammation was unable to be evaluated with objective biochemical markers. In addition, it was a single-center study with 
a limited sample size. Finally, our study included a selected patient population with RA who had moderate disease activity. Therefore, these results cannot be extrapolated to all patients with RA.

In conclusion, our study results suggest that supervised exercise program cannot reduce CVD risk as assessed by the mSCORE, although it improves physical fitness, disease activity, and functional outcomes which may reduce traditional CVD risk factors in patients with RA. We strongly encourage the development of sensitive outcomes measures in this patient population.

\section{Declaration of conflicting interests}

The authors declared no conflicts of interest with respect to the authorship and/or publication of this article.

\section{Funding}

The authors received no financial support for the research and/or authorship of this article.

\section{REFERENCES}

1 Mielants H, Van den Bosch F. Extra-articular manifestations. Clin Exp Rheumatology 2009;275:56-61.

2. Turesson C, O'Fallon WM, Crowson CS, Gabriel SE, Matteson EL. Extra-articular disease manifestations in rheumatoid arthritis: incidence trends and risk factors over 46 years. Ann Rheum Dis 2003;62:722-7.

3. Avina-Zubieta JA, Thomas J, Sadatsafavi M, Lehman AJ, Lacaille D. Risk of incident cardiovascular events in patients with rheumatoid arthritis: a meta-analysis of observational studies. Ann Rheum Dis 2012;71:1524-9.

4. Dhawan SS, Quyyumi AA. Rheumatoid arthritis and cardiovascular disease. Curr Atheroscler Rep 2008;10:128-33.

5. Nurmohamed MT. Atherogenic lipid profiles and its management in patients with rheumatoid arthritis. Vasc Health Risk Manag 2007;3:845-52.

6. Hootman JM, Macera CA, Ham SA, Helmick CG, Sniezek JE. Physical activity levels among the general US adult population and in adults with and without arthritis. Arthritis Rheum 2003;49:129-35.

7. Ozbalkan Z, Efe C, Cesur M, Ertek S, Nasiroglu N, Berneis $\mathrm{K}$, et al. An update on the relationships between rheumatoid arthritis and atherosclerosis. Atherosclerosis 2010;212:377-82.

8. Peters MJ, Symmons DP, McCarey D, Dijkmans BA, Nicola $\mathrm{P}, \mathrm{Kvien} \mathrm{TK}$, et al. EULAR evidence-based recommendations for cardiovascular risk management in patients with rheumatoid arthritis and other forms of inflammatory arthritis. Ann Rheum Dis 2010;69:325-31.

9. de Jong Z, Munneke M, Zwinderman AH, Kroon HM, Jansen A, Ronday $\mathrm{KH}$, et al. Is a long-term high-intensity exercise program effective and safe in patients with rheumatoid arthritis? Results of a randomized controlled trial. Arthritis Rheum 2003;48:2415-24.
10. Baillet A, Zeboulon N, Gossec L, Combescure C, Bodin LA, Juvin R, et al. Efficacy of cardiorespiratory aerobic exercise in rheumatoid arthritis: meta-analysis of randomized controlled trials. Arthritis Care Res (Hoboken) 2010;62:984-92.

11. Koçyiğit H, Aydemir Ö, Fişek G, Ölmez N, Memiş A. Reliability and validity of the Turkish version of ShortForm-36 (SF-36). Turkish J Drugs Therap 1999;12:102-6.

12. Hochberg MC, Chang RW, Dwosh I, Lindsey S, Pincus T, Wolfe F. The American College of Rheumatology 1991 revised criteria for the classification of global functional status in rheumatoid arthritis. Arthritis Rheum 1992;35:498-502.

13. Küçükdeveci AA, Sahin H, Ataman S, Griffiths B, Tennant A. Issues in cross-cultural validity: example from the adaptation, reliability, and validity testing of a Turkish version of the Stanford Health Assessment Questionnaire. Arthritis Rheum 2004;51:14-9.

14. Hisli N. The validity and reliability of the Beck Depression Inventory among. University students. Turkish Journal of Psychology 1989;7:3-13.

15. Enright PL. The six-minute walk test. Respir Care 2003;48:783-5.

16. Anderson J, Caplan L, Yazdany J, Robbins ML, Neogi $\mathrm{T}$, Michaud $\mathrm{K}$, et al. Rheumatoid arthritis disease activity measures: American College of Rheumatology recommendations for use in clinical practice. Arthritis Care Res (Hoboken) 2012;64:640-7.

17. Niemen D. Exercise testing and prescription 7 th ed. New York: McGraw Hill 2011. p. 42-87.

18. Karvonen J, Vuorimaa T. Heart rate and exercise intensity during sports activities. Practical application. Sports Med 1988;5:303-11.

19. Bjarnason-Wehrens B, Mayer-Berger W, Meister ER, Baum K, Hambrecht R, Gielen S. Recommendations for resistance exercise in cardiac rehabilitation. Recommendations of the German Federation for Cardiovascular Prevention and Rehabilitation. Eur J Cardiovasc Prev Rehabil 2004;11:352-61.

20. Stavropoulos-Kalinoglou A, Metsios GS, Veldhuijzen van Zanten JJ, Nightingale P, Kitas GD, Koutedakis Y. Individualised aerobic and resistance exercise training improves cardiorespiratory fitness and reduces cardiovascular risk in patients with rheumatoid arthritis. Ann Rheum Dis 2013;72:1819-25.

21. Myers J, Prakash M, Froelicher V, Do D, Partington $S$, Atwood JE. Exercise capacity and mortality among men referred for exercise testing. $N$ Engl J Med 2002;346:793-801.

22. Keteyian SJ, Brawner CA, Savage PD, Ehrman JK, Schairer J, Divine G, et al. Peak aerobic capacity predicts prognosis in patients with coronary heart disease. Am Heart J 2008;156:292-300.

23. Rouse PC, Veldhuijzen Van Zanten JJ, Metsios GS, Ntoumanis $\mathrm{N}$, Yu CA, Koutedakis $\mathrm{Y}$, et al. Fostering autonomous motivation, physical activity and cardiorespiratory fitness in rheumatoid arthritis: protocol and rationale for a randomised control trial. BMC Musculoskelet Disord 2014;15:445. 
24. Koevoets R, Dirven L, Klarenbeek NB, van Krugten MV, Ronday HK, van der Heijde DM, et al. 'Insights in the relationship of joint space narrowing versus erosive joint damage and physical functioning of patients with RA'. Ann Rheum Dis 2013;72:870-4.

25. van Rensburg DCJ, Fletcher L, Viljoen M, Coertzen C, Grant CC, Ramagole DA, et al. Efficacy of an exercise programme on the functional capacity and disease activity in females with rheumatoid arthritis. SA Orthop J 2010;9:34-43.

26. Kelley GA, Kelley KS, Hootman JM. Effects of exercise on depression in adults with arthritis: a systematic review with meta-analysis of randomized controlled trials. Arthritis Res Ther 2015; 17:21.

27. Walsh NP, Gleeson M, Shephard RJ, Gleeson M, Woods JA, Bishop NC, et al. Position statement. Part one: Immune function and exercise. Exerc Immunol Rev 2011;17:6-63.

28. Chung CP, Oeser A, Avalos I, Gebretsadik T, Shintani A,
Raggi P, et al. Utility of the Framingham risk score to predict the presence of coronary atherosclerosis in patients with rheumatoid arthritis. Arthritis Res Ther 2006;8:186.

29. Rosales-Alexander JL, Salvatierra J, Llorca J, Magro-Checa C, González-Gay MA, Cantero-Hinojosa J, et al. Cardiovascular risk assessment in rheumatoid arthritis: impact of the EULAR recommendations on a national calibrated score risk index. Clin Exp Rheumatol 2014;32:237-42.

30. Gómez-Vaquero C, Robustillo M, Narváez J, RodríguezMoreno J, González-Juanatey C, Llorca J, et al. Assessment of cardiovascular risk in rheumatoid arthritis: impact of the new EULAR recommendations on the score cardiovascular risk index. Clin Rheumatol 2012;31:35-9.

31. Gómez-Vaquero C, Corrales A, Zacarías A, Rueda-Gotor J, Blanco R, González-Juanatey C, et al. SCORE and REGICOR function charts underestimate the cardiovascular risk in Spanish patients with rheumatoid arthritis. Arthritis Res Ther 2013;15:91. 